\title{
LA FOTOGRAFÍA EN BRASIL
}

Querido lector,

Tiene en sus manos un nuevo número de la Revista de Estudios Brasileños, con una sección dedicada a la fotografía en Brasil. El interés por la temática, en parte, es el resultado del esfuerzo del Centro de Estudios Brasileños (CEB) de la Universidad de Salamanca por la promoción de la fotografía brasileña en España. Esta institución hace una labor continua de promoción de la cultura y la ciencia de Brasil en todos los ámbitos, a través de la organización de eventos artísticos y de la divulgación del conocimiento sobre Brasil, uno de los objetivos fundamentales de la REB.

Desde la inauguración de la nueva sede del CEB en 2008, un magnífico edificio barroco completamente reformado en el centro del casco histórico de Salamanca, la sala de exposiciones del Palacio de Maldonado ha acogido una gran cantidad de muestras de autores contemporáneos brasileños.

En estos diez años recorridos desde entonces la fotografía ha sido una constante, con una preferencia por contenidos que trasciendan lo meramente artístico, y aporten una visión de conjunto, complementaria entre ellas, de la sociedad brasileña moderna.

El CEB convoca anualmente, desde 2014, el programa Residencia Artística de Fotografía, para elaborar un catálogo de autores que quieran exponer en Salamanca. El programa debe hacer una selección, debido al amplio número de oferentes, y esto permite una enorme variedad entre propuestas de altísima calidad, todo lo cual redunda en una interactuación del mejor nivel entre el mundo fotográfico brasileño y la esfera académica salmantina.

Gracias a esta experiencia, en el último año (2017) se ha podido contemplar la obra de Zé Barretta a través de la exposición de su proyecto Territorios de Resistencia, que cuenta la problemática de la ocupación de vivienda, o la muestra Labor: Trabajadores de Brasil, de Julio César Pires, de tipo documental pero con una cuidada expresividad. También expusieron su obra Ana Caroline de Lima, con un carácter más antropológico y profundamente humano (Caminhos do Sertão), y la periodista italiana Valeria Saccone, con la intrahistoria de las favelas, en Historias de la Pacificación, con relatos visuales reconstruidos a través de los protagonistas de esa dura historia.

Con un mismo motivo de exploración antropológica se escogió la exposición Nordeste: ausencias y permanencias, de Marcelo Leite, en la que se habla de los retirantes, de la pobreza y de la vida que se abre camino en una de las regiones más pobres del país. También se dedicó espacio a la tradición afrobrasileña con la exposición Os filhos da Terra do Sol, de Raquel Araújo: en ella cupieron las coreiras, las fiestas juninas y el Tambor de Crioula.

La riqueza urbana de Brasil se pudo disfrutar en la exposición compartida Universos Urbanos, de Renan William Candido, Marcio Salata y Camila Guimarães, todo un ejercicio de composición, expresión y colorido, y en la llamativa propuesta O Rio que eu piso, de Bruno Veiga, en la que se fotografía el sorprendente suelo carioca, sus sombras, sus texturas, las narrativas que encierran los conjuntos del pavimento.

En la línea de la implicación social que debe tener la universidad, y con la intención de subrayar la importancia de la semántica de la imagen además de a su propio e intrínseco valor artístico, el CEB ha aportado un hito relevante: en 2015, albergó la primera exposición fotográfica sobre la reciente Comisión Nacional de la Verdad, con 150 fotografías procedentes de sus fondos, escogidas y comisariadas por Vivien Ishaq, como 
parte de un proyecto académico más amplio, que incluye la traducción y edición de una parte del Informe final de la Comisión.

Otra de las grandes experiencias en la corta vida del CEB ha sido la muestra Esencias de Brasil. Mares, ríos, gentes, ciudades (2014), celebrada con motivo de los 50 años de la Casa de Brasil de Madrid. Supuso un punto de inflexión por el excelente resultado final y por una gestación larga y bien cuidada: un concurso fotográfico promovido por la Embajada de Brasil proporcionó un ganador por cada Estado y otro por el Distrito Federal. Con las 27 fotografías resultantes se compuso a muestra itinerante, 27 miradas, que fue el germen de la exposición vista en el CEB, y supuso un éxito de organización y repercusión.

También pasaron en años anteriores por la sala de exposiciones del CEB Augusto Pessoa, con su evocador viaje Brasil Profundo (2015); el poético ensayo fotográfico Izabel, de Ángela Sairaf (2016); la visión de la mujer que tenía Chico Buarque, a través de los ojos de Socorro de Araújo (A poética femenina de Francisco, 2009) o el mundo de las drag queens de Florianópolis, retratado por Camila Chittolina (Drag Queen, del tenis al zapato de tacón, 2010).

Por otra parte, la fotografía es una experiencia de la que también se ha hecho partícipes a los alumnos universitarios que tienen relación con el CEB, y que son los alumnos Pro-UNI, brasileños becados en España. La exposición Miradas y Sonrisas contó con una treintena de retratos realizados por los alumnos del curso 2013-2014.

La labor editorial relacionada con la fotografía y promovida por el CEB ha tenido, además de este presente volumen, otros dos magníficos resultados: los libros Salamanca en fotografías, de Guilherme Colares, y Sertão, um espaço construído, de Batira Barbosa y Socorro Ferraz.

Cuando se cumplen los diez años del uso autónomo de la sala de exposiciones del Palacio de Maldonado, la vista atrás es obligada. Y el panorama que se observa es un camino recorrido, jalonado de buenos recuerdos. Pero si se vuelve la mirada adelante, el camino por recorrer es largo, atractivo y lleno de posibilidades. La fotografía brasileña es todo un mundo extremadamente complejo, lleno de ricos matices y sumamente apetecible.

El presente Dossier Fotografía Brasileña presenta una pequeña muestra de la extensa, fecunda y diversa producción académica brasileña en el campo de la fotografía en los últimos diez años. En ese periodo, la fotografía ha consolidado su lugar en el campo académico en varias áreas del conocimiento científico, como Arte, Antropología, Sociología, Historia, Letras y Comunicación Social, entre otras. Pero también, ha consolidado su posición en el campo de las Artes Visuales, recibiendo espacio en las exposiciones, galerías y colecciones de museos de arte.

Ha sido muy difícil seleccionar solo algunos textos de entre el conjunto amplio y cualificado de artículos que se presentaron al Dossier. Lo que demuestra la expansión y la consolidación del campo de investigación sobre la fotografía y su presencia en diferentes programas de post graduación en la actualidad.

La elección de los artículos procuró tener en cuenta temar recurrentes en el corpus de trabajos presentados y que también reflexionasen sobre áreas de investigación estratégicas para la historia y el debate teórico sobre la fotografía brasileña.

Los investigadores que trabajan con el siglo XIX y la primera mitad del siglo XX observan la preponderancia del retrato y el paisaje en la producción de los estudios y en los acervos fotográficos públicos y privados brasileños. En ese sentido, el artículo Retratos do Brasil Contemporâneo: práticas fotográficas nos séculos XIX e XX, de Ana Maria Mauad (UFF), Mariana Muaze (UNIRIO) y Marcos Felipe de Brum Lopes (MCBC/IBRAM) propone un panorama sobre los estudios, las colecciones y las investigaciones en el área, visando comprender el papel que la fotografía ha asumido en la cultura visual brasileña. 
En la investigación actual en el área de la fotografía, de las Artes Visuales y en el conjunto de trabajos presentados, se observa el predominio de cuestiones que aluden a la identidad, alteridad y género. O gênero da fotografia: da intersubjetividade à intercorporalidade na obra de Alair Gomes, artículo de Ivaldo Gonçalves de Lima (UFF), aborda las tres cuestiones y las ubica en el espacio de la ciudad de Río de Janeiro de los años 1960-1970, para comprender la tríada sujeto/arte/espacio y cómo el entorno socio-espacial de Ipanema, recreado por el arte de Alair, expresa el desplazamiento de una intersubjetividad hacia una intercorporalidad. Las fotografías de Alair Gomes se han expuesto en Brasil y en otros países en los últimos años, habiendo inspirado también trabajos de gran impulso en el campo de las artes visuales como los de Alexandre Santos (UFRGS) y Cezar Tadeu Bartholomeu (UFRJ).

Otro desafío de las investigaciones sobre fotografía brasileña es conectar los sujetos, las trayectorias, las prácticas, las técnicas y los espacios expositivos al campo más amplio de una historia internacional de la fotografía. La investigación sobre la fotografía, los fotógrafos y sus poéticas visuales en los años 1970 y 1980 , apunta a largos periodos de formación, conocimiento de la producción, de las formas de organización y de los repertorios imagéticos de otros artistas y fotoperiodistas de América Latina, Europa y Estados Unidos. En ese sentido, el artículo Os Colóquios Latino-Americanos de Fotografia e a institucionalização de uma fotografia brasileira, de Erika Zerwes (MAC/USP) y Eduardo Augusto Costa (UNICAMP) aborda simultáneamente el proceso de institucionalización de la fotografía brasileña con la creación del Núcleo de Fotografía/Instituto Nacional de Fotografía de FUNARTE y la participación de fotógrafos brasileños en los Coloquios Latinoamericanos de Fotografía en 1978 y 1981 en Ciudad de México. Estos coloquios posibilitaron el diálogo entre fotógrafos e instituciones brasileñas y latinoamericanas, permitiendo que se exportaran a América Latina experiencias institucionales europeas y norteamericanas, al mismo tiempo en que se divulgaba en Europa la fotografía latinoamericana.

\section{COORDINADORES}

\section{Charles Monteiro}

Profesor de Historia de la Pontifícia

Universidade Católica de Rio Grande do Sul (Brasil)

\section{Pablo Rey}

Profesor de Fotografía Publicitaria, Artística y de Periodismo gráfico de la Universidad Pontificia de Salamanca

preyga@upsa.es 